\title{
Propranolol and Practolol in the Treatment of Spontaneous Angina Pectoris
}

\author{
Maurizio Guazzi, M.D., Alvise Polese, M.D., Fabio Magrini, M.D., \\ and Cesare Fiorentini, M.D.
}

\begin{abstract}
SUMMARY
In a comparative trial practolol was found to be quite superior to propranolol in the treatment of spontaneous angina pectoris. Propranolol did not reduce the number of anginal attacks in the 24 hours, as evaluated through the patients' charting and continuous electrocardiographic recording, and induced exaggerated bradycardia as well as clinical and hemodynamic signs of poor cardiac performance. In the same patients practolol achieved complete disappearance of the anginal attacks, and returned cardiac function to quite satisfactory levels. The forcedly low doses might be one of the possible reasons of the failure of propranolol.

The attacks of the angina here investigated occurred at rest and in absence of any detectable eliciting factor. They were not triggered by circulatory modifications interfering with the oxygen requirement of the heart. These findings make the favorable therapeutic response to betablockade of difficult interpretation on the basis of the mechanisms usually indicated for the antianginal action of these drugs, and suggest that some other, still unknown effect must be at work.
\end{abstract}

\section{Additional Indexing Words:}

Cardiac function Continuous electrocardiographic recording

R $\mathrm{Y}$ spontaneous angina pectoris we mean the following: chest pains coming at rest, sensitive to nitroglycerin, not related to detectable eliciting factors, accompanied by reversible unequivocal electrocardiographic alterations. The latter may be of 2 different types: a) S-T elevation in some leads with reciprocal depression in the opposite leads, what is peculiar of the variant form of angina pectoris described by Prinzmetal et al;1) b) Ischemic S-T segment depression in the leads reflecting left ventricular epicardial potentials, which is the common pattern of angina pectoris.

The therapeutic effect of beta-blockade in angina pectoris has widely been investigated. ${ }^{2-5)}$ The response to beta-blockers of patients with spontaneous angina, however, may reveal mechanisms for the antianginal action of

From the Centro Ricerche Cardiovascolari del Consiglio Nazionale delle Ricerche, Istituto di Clinica Medica II and Istituto Ricerche Cardiovascolari, University of Milano, Milano, Italy.

Received for publication September 18, 1972. 
these drugs different from those usually suggested in angina of effort. The study appeared of interest also in view of the notorious difficulty to evaluate the efficacy of any form of therapy of patients with angina, since almost any intervention may be associated with symptomatic improvement. ${ }^{6)}$ Patients with spontaneous angina occurring repeatedly during the 24 hours, are particularly suitable for testing the efficacy of the treatment in objective terms through a continuous electrocardiographic recording.

The therapeutic response to propranolol of patients with Prinzmetal's angina has been reported previously. ${ }^{71}$ The present investigation concerns patients with spontaneous angina showing the second type of electrocardiographic pattern.

\section{Patients and Methods}

\section{Patients}

Patients were selected who had a history of chest pains of typical quality and location, usually coming at rest without any precipitating factor, recurring in a cyclic waxing and waning fashion and often occurring at approximately the same time each day. Their symptoms had begun from a few months to a year before the admission, and had become worse during the last weeks. Nine such cases of

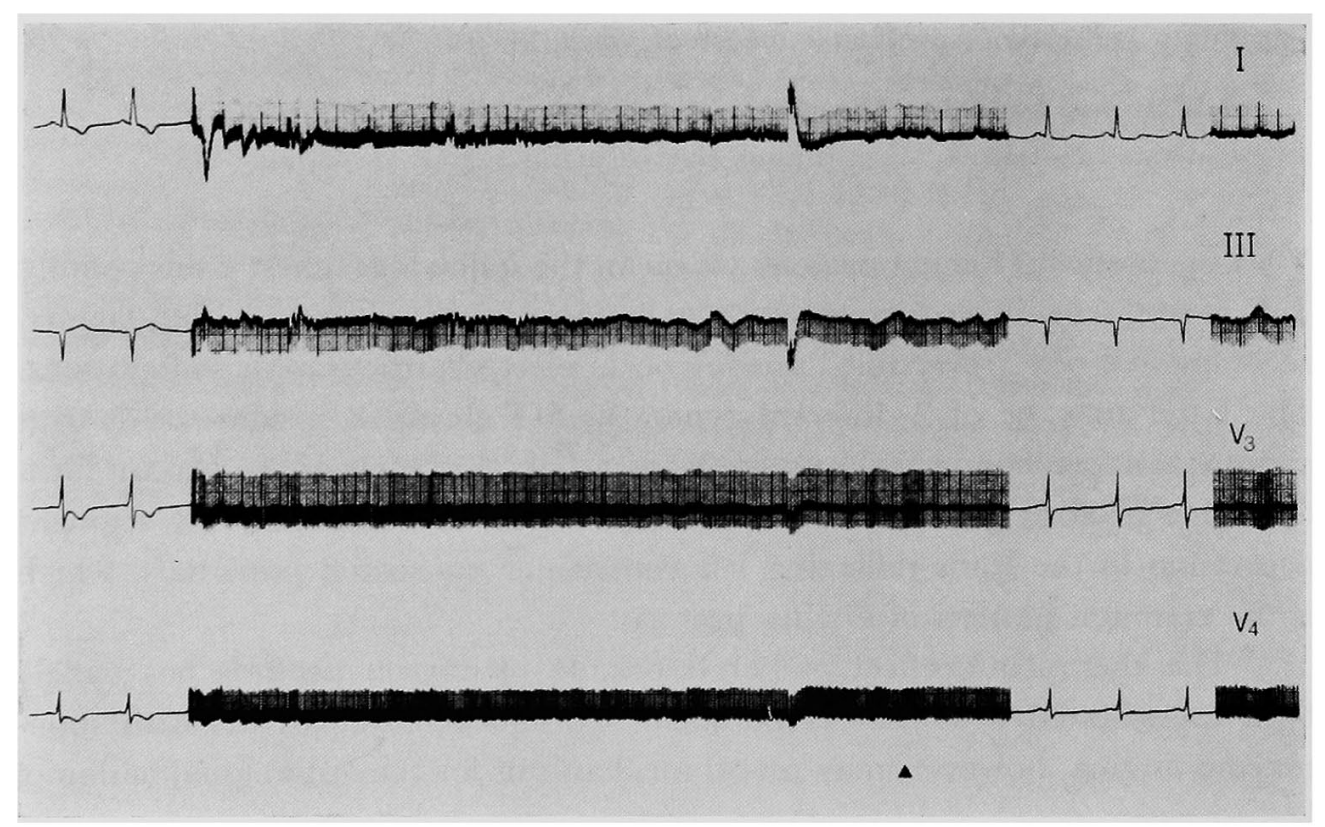

Fig. 1. Continuous recording at different speeds of 4 electrocardiographic leads during the waning phase of an anginal attack. The end of the episode is signalled by the arrowhead. The progressive reversion to the isoelectric line of the S-T tract appears quite evident in $V_{3}$. 
angina have so far been investigated. The basal electrocardiogram was normal in 4 subjects, in 3 it revealed old myocardial infarction, and in 2 it showed flat $T$ waves in the lateral precordial leads. Fig. 1, which reproduces the waning phase of an anginal attack, shows an example of these changes. The latter were so clear as to make unequivocal the identification of the single episodes, during continuous electrocardiographic recording, even at very low paper speed.

\section{Investigation}

The subsequent steps of the investigation were the same as already reported in details." In summary the study was arranged as follows. a) Daily charting, throughout the hospital period, of the number, time and circumstances of the anginal attacks. b) Continuous electrocardiographic recording, after the first week of stay in the hospital, during those hours in which the daily charting had indicated the anginal episodes most likely to occur. In each case the study lasted from 6 to 8 hours. c) Oral administration of propranolol in an initial daily dosage of $40 \mathrm{mg}$, which was subsequently increased by $40 \mathrm{mg}$ every other day, according to the patient's response. Because the response appeared unsatisfactory, propranolol therapy was interrupted when the daily dosage was still rather low (maximal doses ranging from 120 to $240 \mathrm{mg}$ a day). d) Repeat of the electrocardiographic study during the same hours as before treatment. e) Oral administration of practolol, started at a daily dose of $100 \mathrm{mg}$ and increased by $100 \mathrm{mg}$ every other day, according again to the clinical response. No adverse effect precluded the required increments and the final dosage could be individualized to achieve complete relief of the angina. f) $R e-$ peat of the continuous electrocardiographic recording during the same hours as before treatment, after 1 week of complete absence of anginal pain reports in the patients' charting. g) Discharge under practolol treatment at the individual doses which had induced optimal therapeutic effect, and beginning of a long-term followup.

In order to assess the circulatory pattern of these anginal attacks as well as the influence of the treatment on the basal left ventricular function, hemodynamic studies were carried out in 4 patients before any therapy and after practolol. In 2 of them the procedure was performed also after propranolol. According to the method previously reported, ${ }^{8}$ ' heart rate, arterial pressure and right atrial pressure were continuously recorded both in the basal state and during anginal attacks. Cardiac index, systemic vascular resistance, left ventricular mean systolic ejection rate, mean rate of isovolumic pressure development, minute work, and tension time index per minute were also evaluated.

\section{RESULTS}

Three patients suddenly died in the course of anginal attacks during the first days of hospital stay, before any treatment. In 2 of them ventricular fibrillation could be documented and the resuscitative maneuvers resulted uneffective.

Table I shows the incidence of angina charted by the patients in the 24 hours and during the hours of continuous ECG recording, before and after 
Table I. Incidence of Anginal Pains Charted by the Patients in the 24 Hours, and Episodes of ECG Alterations during the Continuous Electrocardiographic Recording, before and after Propranolol and Practolol Treatment

\begin{tabular}{c|c|c|c|c|c|c|c|c}
\hline \multirow{2}{*}{$\begin{array}{c}\text { Case } \\
\text { No. }\end{array}$} & \multicolumn{2}{|c|}{ Control } & \multicolumn{3}{c|}{ Propranolol } & \multicolumn{3}{c}{ Practolol } \\
\cline { 2 - 9 } & $\begin{array}{c}\text { Reports } \\
\text { 24 hours }\end{array}$ & $\begin{array}{c}\text { ECG } \\
\text { study }\end{array}$ & (mg/day) & $\begin{array}{c}\text { Reports } \\
\text { 24 hours }\end{array}$ & $\begin{array}{c}\text { ECG } \\
\text { study }\end{array}$ & (mg/day) & $\begin{array}{c}\text { Reports } \\
\text { 24 hours }\end{array}$ & $\begin{array}{c}\text { ECG } \\
\text { study }\end{array}$ \\
\hline 1 & $3-4$ & 2 & 240 & $2-4$ & 1 & 700 & none & none \\
2 & $4-5$ & 2 & 120 & $3-5$ & 2 & 800 & none & none \\
3 & $3-4$ & 2 & 120 & $2-5$ & 2 & 500 & none & none \\
4 & $8-10$ & 3 & 240 & $6-15$ & 2 & 500 & none & none \\
5 & $6-7$ & 3 & 160 & - & - & - & - & - \\
6 & $4-5$ & 1 & 120 & $4-5$ & 2 & 400 & none & none
\end{tabular}

The daily doses of either drug are also indicated for each patient.

either kind of treatment. One patient (Case No. 5) died from cardiac arrest during an episode of angina while in treatment with propranolol. At that time the daily dose was $160 \mathrm{mg}$, which was ineffective in reducing the number of pain reports. In the other 5 patients propranolol administration was interrupted at the dosage indicated in Table I. Further increments were judged unadvisable for the following reasons: no significant reduction in the anginal episodes had been observed parallel with the progressive increase of propranolol dosage; in one patient (Case No. 4) their occurrence had become somewhat higher; pulse rate had obviously reduced (in some case less than $50 \mathrm{~b} / \mathrm{min}$ ); cardiac function was depressed as to induce some degree of nocturnal dyspnea in all of the patients, and basilar lung rales in 2 cases.

Following practolol administration, parallel with the increment of the dosage, a progressive decrease of the number and severity of the anginal episodes, as well as of nitroglycerin consumption was observed. In each patient a daily dosage could be reached which was effective in abolishing any pain report. The electrocardiographic study, repeated after practolol administration, revealed no modification from its basal appearance throught the hours of continuous recording. While on practolol, none of the patients complained nocturnal dyspnea, and no sign of pulmonary congestion became manifest.

Table II summarizes the circulatory data before and after either kind of treatment. After practolol administration, the following modifications, as compared to the pretreatment control, were detected: constant decrease in heart rate; slight reduction or no change in right atrial pressure; not homogeneous variations in arterial pressure, cardiac index, systemic vascular resistance, left ventricular mean systolic ejection rate, mean rate of isovolumic 
Table II. Circulatory Parameters before Treatment (a), after Propranolol (b), and after Practolol (c)

\begin{tabular}{|c|c|c|c|c|c|c|c|c|c|}
\hline $\begin{array}{l}\text { Case } \\
\text { No. }\end{array}$ & $\begin{array}{c}\text { Heart } \\
\text { rate } \\
\text { (beats/ } \\
\text { min) }\end{array}$ & $\begin{array}{c}\text { Mean } \\
\text { arterial } \\
\text { pressure }\end{array}$ & $\begin{array}{l}\text { Mean } \\
\text { rt. atrial } \\
\text { pressure }\end{array}$ & $\begin{array}{c}\text { Cardiac } \\
\text { index } \\
\mathrm{ml} / \mathrm{min} / \\
\mathrm{M}^{2}\end{array}$ & $\begin{array}{l}\text { Systemic } \\
\text { periph. } \\
\text { resistance } \\
\text { (dynes. } \\
\sec \cdot \mathrm{cm}^{-5} \text { ) }\end{array}$ & $\begin{array}{l}\text { Mean } \\
\text { syst. } \\
\text { ejection } \\
\text { rate } \\
(\mathrm{ml} / \mathrm{sec} / \\
\left.\mathbf{M}^{2}\right)\end{array}$ & $\begin{array}{c}\text { Mean } \\
\text { rate } \\
\text { isovol. } \\
\text { pressure } \\
\text { develop; } \\
\text { (mmHg/ } \\
\text { msec) }\end{array}$ & $\begin{array}{c}\text { Left } \\
\text { ventric. } \\
\text { work } \\
(\mathrm{Kpm} / \\
\left.\mathrm{min} / \mathrm{M}^{2}\right)\end{array}$ & $\begin{array}{c}\text { Tension } \\
\text { time } \\
\text { index } \\
\text { (mmHg/ } \\
\text { min })\end{array}$ \\
\hline $1 \mathrm{a}$ & 81 & 81 & 5 & 3,170 & 1,123 & 150 & 1.8 & 2.56 & 2.063 \\
\hline b & 54 & 83 & 8 & 2,700 & 1,303 & 140 & 1.8 & 2.26 & 1,939 \\
\hline c & 80 & 93 & 4 & 3,000 & 1,390 & 144 & 2.8 & 2.80 & 2,576 \\
\hline $2 a$ & 60 & 94 & 10 & 2,520 & 1,330 & 144 & 1.2 & 2.40 & 1,680 \\
\hline b & 48 & 88 & 13 & 2,110 & 1,420 & 135 & 1.0 & 2.28 & 1,510 \\
\hline c & 53 & 104 & 10 & 2,420 & 1,548 & 134 & 1.5 & 2.52 & 2,050 \\
\hline $3 \mathrm{a}$ & 72 & 100 & 5 & 3,370 & 900 & 156 & 2.1 & 3.38 & 2,937 \\
\hline c & 63 & 107 & 5 & 2,900 & 1,120 & 144 & 1.6 & 3.09 & 2,792 \\
\hline 4 a & 90 & 125 & 7 & 2,610 & 1,745 & 115 & 2.2 & 3.26 & 3,270 \\
\hline c & 78 & 109 & 5 & 3,430 & 1,170 & 182 & 1.9 & 3.70 & 2,302 \\
\hline
\end{tabular}

pressure development, minute work and tension time index. In the 2 patients who were investigated both in the control state and after either therapeutic regimen, the reduction in cardiac index operated by propranolol was greater than following practolol. Mean right atrial pressure increased after the former drug and returned to the control values after the latter. These observations were in agreement with the clinical symptoms.

At the present time the periods of follow-up vary from 5 to 12 months. All of the patients are still on practolol without any remarkable side effect. Two remained free of symptoms up to the time of writing. In 3 the reappearance of mild chest pains required some increment of beta-blocker which resulted quite effective. Nitroglycerin consumption has been reduced to 3-4 tablets per month in each of these subjects. Particularly impressive is a patient (Case No. 4) who after discharge took 28 tablets of glyceryl trinitrate in 10 months, after having taken 265 tablets during the 25 days of his hospital stay.

\section{Discussion}

Practolol therapy appeared quite effective in this form of angina. A symptomatic effect can be excluded, in our opinion, for the following reasons: were it matter of mere placebo effect, a positive response should have become manifest also after propranolol, which, on the contrary, was ineffective; the 
improvement was obviously dose-dependent; after adequate dose of practolol, coincident with the relief of the subjective symptoms, a complete disappearance of the phasic electrocardiographic abnormalities was seen.

The long-term follow-up confirmed the positive results and further emphasized that the antianginal effects of practolol are strictly dose-dependent.

The circulatory basis for the favourable clinical effects of beta-blockade in the treatment of patients with angina pectoris is analyzed ${ }^{9)}$ in the context of the relative balance of myocardial oxygen delivery and demands. Since anginal pain occurs when myocardial $\mathrm{O}_{2}$ requirements exceed the capacity of the coronary system to deliver $\mathrm{O}_{2}$, the success of the beta-blockade is interpreted as dependent upon the favourable alterations of this imbalance, through a reduction of heart rate, arterial pressure, velocity of myocardial contraction. The electrocardiographic alterations of the attacks of angina here reported occurred at rest, in absence of detectable eliciting factors, and, as shown through the circulatory studies, were not preceded and consequently not triggered by changes of hemodynamic parameters closely related to the oxygen requirements of the heart (such as heart rate, arterial pressure, cardiac output, duration of left ventricular contraction). Furthermore, the success of the drug cannot be explained on the basis of the changes induced in basal blood pressure, left ventricular work and tension time index, the values of these parameters being in some case higher after treatment than before. These reasons make the suggested mechanisms of action of the beta-blockers, which are quite reasonable in angina on effort, unsatisfactory for spontaneous angina, and indicate that these mechanisms are still not completely understood. Any interpretation will probably remain only speculative as long as the trigger factors of this kind of anginal attacks will not be clear.

Practolol, as compared to propranolol, induced a minor degree of bradycardia and less depressive effects on cardiac function. These findings are in good agreement with the hemodynamic reports of other authors. ${ }^{10)-12}{ }^{12}$

An important question is: does a real difference exist between propranolol and practolol in the treatment of angina pectoris? Our data would appear in contrast with those of Prichard et al, ${ }^{13)}$ and of Sandler and Clayton ${ }^{14)}$ who observed better results with propranolol. George et al $^{15)}$ found practolol almost effective as propranolol. They reported the case of a patient who did not respond to propranolol and who did respond to practolol, and proposed the possibility that one beta-blocking agent may produce beneficial effects where another has failed. A comparison between findings in angina on effort, and the present ones in spontaneous angina, does not seem fully appropriate. On the basis of our own data, we consider the question not definitely answerable because the different response to the 2 beta-blockers might merely be due 
to the forcedly low doses of propranolol.

The favourable results obtained with propranolol in Prinzmetal's angina") and the findings of the present study might suggest a different indication of propranolol and practolol in different kinds of spontaneous angina pectoris. Further investigations with crossed administration of the 2 drugs will help to clarify the problem.

\section{REFERENCES}

1. Prinzmetal M, Kennamer R, Merliss R, Wada T, Bor N: Am J Med 27: 375, 1959

2. Hamer J, Sowton E: Am J Cardiol 18: 354, 1966

3. Gianelly RE, Goldman RH, Teister B, Harrison DG: Ann Intern Med 67: 1216, 1967

4. Hebb AR, Godwin TF, Gunton RW: Canad Med Assoc J 98 : 246, 1968

5. Amsterdam EA, Gorlin R, Wolfson S: JAMA 210: 103, 1969

6. Beecher HK: JAMA 158: 399, 1955

7. Guazzi M, Magrini F, Fiorentini C, Polese A: Brit Heart J 33: 889, 1971

8. Guazzi M, Polese A, Fiorentini G, Magrini F, Bartorelli C: Brit Heart J 33: 84, 1971

9. Epstein SE, Braunwald E: Med Clin North America 52 1031, 1968

10. Sowton E, Balcon R, Cross D, Frick H: Brit Med J 1: 215, 1968

11. Jewitt DE, Burgess PA, Shillingford JP: Cardiovasc Res 4: 188, 1970

12. Leon DF, Thompson ME, Shaver JA, McDonald RH: Circulation 45: 46, 1972

13. Prichard BNG, Lionel NDW, Richardson GA: Postgr Med J (suppl) 47:59, 1971

14. Sandler G, Clayton GA: Brit Med J 2: 399, 1970

15. George CF, Nagle RE, Pentecost BL: Brit Med J 2: 402, 1970 